\title{
RETINITE POR CITOMEGALOVÍRUS EM PACIENTES PEDIÁTRICOS INFECTADOS PELO VÍRUS DA IMUNODEFICIENCIA HUMANA EM TRATAMENTO COM "HIGHLY ACTIVE ANTIRETROVIRUS THERAPY"
}

\author{
Maria Angélica Dimantas*, luciana Peixoto Finamor, Vânia Ewert, Célia Nakanami, Cristina Muccioli \\ Trabalho realizado no Departamento de Oftalmologia da Universidade Federal de São Paulo - \\ Escola Paulista de Medicina, São Paulo, SP.
}

RESUMO - Objetivo. Descrever uma série de casos de retinite pelo citomegalovírus (CMV), na população pediátrica infectada pelo vírus da imunodeficiência humana (HIV), em tratamento com inibidores de protease e inibidores da transcriptase reversa (HAART), que apresentaram falência terapêutica e ausência de resposta aos antivirais utilizados no tratamento do CMV.

MétOdos. Três pacientes pediátricos portadores da síndrome da imunodeficiência humana (AIDS), em tratamento com HAART, foram submetidos a exame oftalmológico em um centro universitário de referência - UNIFESP.

Resultados. Os três pacientes do sexo masculino apresentavam média de idade de seis anos (variando entre 10 meses e I3 anos) e todos pertenciam à classificação C3 (CDC - Atlanta - EUA 1994). A média obtida entre a contagem de linfócitos $\mathrm{CD} 4+$ dos três casos foi de $67 \mathrm{cel} / \mathrm{mm}^{3}$ (variando entre $43-98 \mathrm{cel} / \mathrm{mm}^{3}$ ); e a média da carga viral foi de 190.000 cópias/ml (variando entre 53.600 . 460.000 cópias $/ \mathrm{ml})$.
Os três pacientes desenvolveram resistência ao uso dos antiretrovirais análogos de nucleosídeos inibidores da transcriptase reversa e aos inibidores de protease (HAART), e em todos os casos foram utilizados antivirais específicos para o tratamento da retinite pelo CMV sem sucesso.

Conclusöes. Os benefícios obtidos desde a introdução da era HAART são, sem dúvida, sem precedentes dentro do quadro evolutivo da AIDS. 0 início da falência terapêutica observado com relação às drogas do HAART tem colaborado de maneira decisiva para o surgimento de casos de retinite pelo CMV tão agressivos quanto os observados na era pré-HAART. 0 exame de rotina para pacientes pediátricos torna-se fundamental, tanto pela escassez de estudos realizados neste grupo específico, quanto pela importância de seu prognóstico visual.

UNITERMOS: AIDS. Criança. HAART/ falência tratamento. Retinite por citomegalovírus/ tratamento. Relato de caso.

\section{INTRODUÇÃO}

Alterações oculares têm sido descritas em pacientes infectados pelo vírus da imunodeficiência humana (HIV) desde a década de 80, em diversos estudos que apresentam resultados semelhantes em todo o mundo ${ }^{1,2}$

Com a introdução do uso combinado de antiretrovirais inibidores de protease e de inibidores nucleosídeos da transcriptase reversa, deu-se início à denominada "era HAART" (Highly Active Antiretroviral Therapy). A partir de 1996, observou-se, então, um novo padrão de comportamento com relação à morbidade e mortalidade dos pacientes infectados pelo HIV. A evolução natural das infecções oportunistas também

* Correspondência Rua Botucatu, 822 - CEP: 04023-062 - São Paulo - SP Tel.: (11) 5085-2027 madimantas@oftalmo.com.br sofreu importante mudança ${ }^{3}$. $\bigcirc$ aumento dos níveis de linfócitos CD4 + e a diminuição da carga viral (CV), promovidos pela terapia, parecem estar diretamente relacionados a esses achados ${ }^{4}$

Várias infecções oportunistas tiveram sua morbidade alterada após a era HAART, como por exemplo, a pneumonia por Pneumocystis carinii (PCP), a criptococose, a infecção pelo Mycobacterium avium complex, a toxoplasmose e a retinite pelo citomegalovírus (CMV) ${ }^{5}$.

A retinite causada pelo citomegalovírus (CMV) é a infecção ocular oportunista mais comum entre adultos infectados pelo vírus da imunodeficiência humana (HIV), tendo sido amplamente estudada nesta população. É considerada a principal causa de cegueira associada à AIDS neste grupo 6,7. Tipicamente, manifesta-se como uma complicação tardia da Síndrome da Imunode ficiência Adquirida (AIDS), cuja incidência e risco de desenvolvimento aumentam nos pacientes com depleção severa de linfócitos CD4+ (valores abaixo de 100 e principalmente abaixo de 50 cels $\left./ \mathrm{mm}^{3}\right)^{8}$. Sua incidência antes da era HAART variava em torno de 40\%\%. Atualmente, observamos diminuição importante da incidência da retinite pelo CMV, variando entre $5 \%$ e $20 \%{ }^{10,11}$, dependendo da população estudada.Tal retinite, quando não tratada, progride, resultando em perda visual irreversível.

Entre os pacientes pediátricos, a incidência de retinite por CMV varia entre 1,6\% a 5\% 12,13 , dependendo da população estudada e da introdução ou não da associação entre inibidores de protease e inibidores da transcriptase reversa, utilizados no HAART.

O objetivo deste estudo é descrever três casos de pacientes pediátricos portadores do vírus da imunodeficiência humana (HIV), com retinite pelo citome galovírus (CMV), de alta agressividade na vigência do tratamento com HAART. 


\section{Métodos}

Relato de três pacientes pediátricos portadores do HIV encaminhados ao Setor de Uveítes e AIDS da Universidade Federal de São Paulo (UNIFESP), para avaliação oftalmológica, em tratamento com inibidores de protease e análogos de nucleosídeos inibidores da transcriptase reversa (HAART). Os três pacientes apresentavam falência terapêutica ao tratamento com HAART .

\section{Caso I}

\section{Relato de Casos}

L.F.O, masculino, 10 meses, pardo, infec tado pelo HIV por transmissão vertical, SIDA C3 (Classificação CDC, 1994). Paciente internado com infecção pulmonar de etiologia indeter minada e hepatite C. Em uso de 3TC, d4T e Nelfinavir, Bactrim ${ }^{\circledR}$ e Anfotericina B. Contagem de linfócitos CD4+ 43 cels $/ \mathrm{mm}^{3}$, carga viral 53.600 cópias/ml; antigenemia positiva para CMV.

A fundoscopia apresentava olho direito sem alterações e perivasculite nas arcadas temporal superior e inferior do olho esquerdo (FOTO I). Foi feito o diagnóstico de retinite por CMV (forma frosted branch angiitis) e introduzido ganciclovir (dose de ataque). Após 10 dias o exame fundoscópico mostrava acometimento bilateral das arcadas vasculares retinianas com retinite granular perivascular e oclusão de ramo arterial no olho esquerdo. Seu comprometimento sistêmico impossibilitou a realização de controle retinográfico. Com o evidente quadro de progressão da retinite e gravidade dos efeitos colaterais produzidos pelo ganciclovir, como a neutropenia e plaquetopenia, optou-se pela substituição por foscarnet $20 \mathrm{mg} / \mathrm{kg} / \mathrm{d}$ por 21 dias. Confirmou-se, através da genotipagem do HIV, sua resistência completa aos antiretrovirais que estavam sendo utilizados no tratamento.

Após cinco dias, o paciente evoluiu com agravamento do quadro sistêmico, indo a óbito antes que pudesse ser realizada alteração das drogas antiretrovirais.

\section{Caso 2}

W.A.O., masculino, seis anos, pardo, infectado pelo HIV (transmissão vertical), SIDA C3. Paciente em tratamento com DDI, d4T e ritonavir; foscarnet em dose de manutenção (tratado previamente com dose de ataque por 21 dias); Bactrim ${ }^{\circledR}$, fluconazol e azitromicina,

\section{Figura I - Retinografia evidenciando embainhamento vascular atingindo artérias} e veias do olho esquerdo. "Frosted Branch Angiitis"

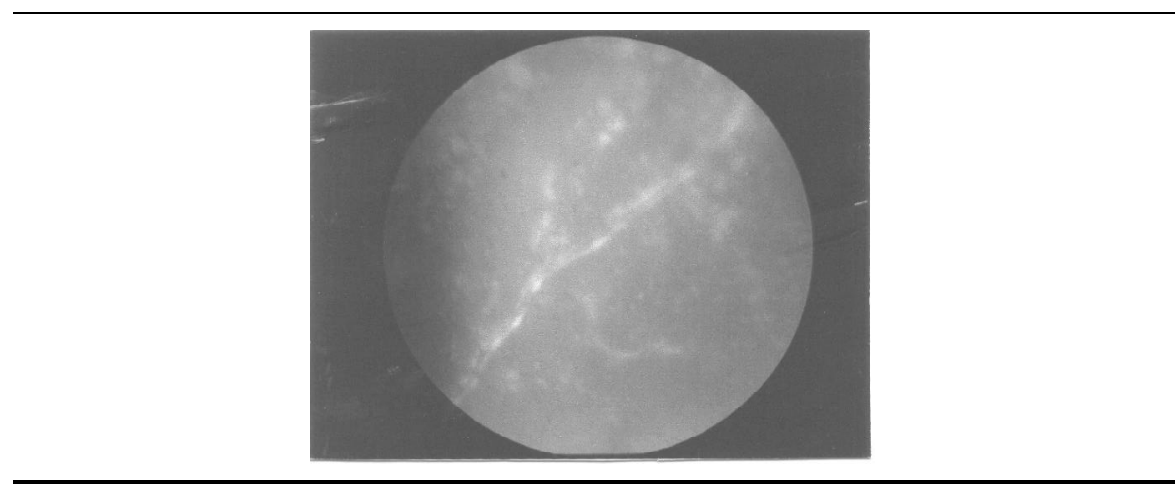

Figura 2 - Retinografia do olho direito evidenciando áreas de fibrose acompanhando as arcadas vasculares e alterações retinianas maculares. (Forma cicatricial CMV)



em vigência de hepatite aguda medicamentosa. $\mathrm{Na}$ época do exame, apresentava linfócitos CD4+ 59 cels/mm³ e CV: 55.876 cópias $/ \mathrm{ml}$.

Ao exame oftalmológico, apresentava acuidade visual de 20/200 no olho direito e percepção luminosa no olho esquerdo. A biomicroscopia do olho direito apresentava-se sem alterações e catarata subcapsular posterior no olho esquerdo. À oftalmoscopia indireta sob midríase, observamos no olho direito: papila pálida, cicatrizes retinianas difusas e fibrose de pólo posterior. O olho esquerdo apresentava descolamento de retina temporal e neovasos na região nasal, não sendo possível evidenciar sinais de retinite em atividade. (Foto 2).

Atualmente (após seis meses de evolução), apresenta resistência a todos os antiretrovirais testados (confirmada através de genotipagem) e também ao foscarnet. Com a melhora das funções renal e hematológica, optou-se por manter o ganciclovir em dose de manutenção para tentar manter a acuidade visual atual e evitar disseminação hematogênica com conseqüente comprometimento pulmonar e risco de óbito.

\section{Caso 3}

F.A.J., masculino, 13 anos, infectado pelo HIV (transmissão vertical), SIDA C3. Paciente em tratamento com 3TC, d4T e Nevirapine (apresentou resistência ao ritonavir e saquinavir); Bactrim $\AA^{\circledR}$, etambutol, claritromicina. CD4+ :98 cels/ $/ \mathrm{mm}^{3}$ e CV: 460.000 cópias $/ \mathrm{ml}$. Antecedente de doença ocular prévia causada pelo herpes $(3 / 4)$ necrose progressiva da retina externa (PORN) (3/4) em ambos os olhos. Ao exame oftalmológico apresentava no olho direito acuidade visual de percepção luminosa e no olho esquerdo 20/30. Iniciou quadro de necrose retiniana envolvendo a mácula com descolamento de retina e hemorragia vítrea no olho esquerdo (lesão compatível com retinite pelo CMV). Apresentou contra-indicação clínica para o uso de ganciclovir EV (neutropenia e disfunção renal), optandose pela injeção intravítrea de ganciclovir e valaciclovir. O paciente evoluiu com acuidade visual de percepção luminosa. (Fotos 3 e 4).

Apresentou resistência a todos os antiretrovirais utilizados (confirmada pela genotipagem). Optou-se pela introdução de foscarnet 
em dose de manutenção para evitar uma possível disseminação sistêmica do citomegalovírus, visto que suas lesões retinianas permaneciam estáveis. A despeito de todas as tentativas para manutenção das condições clínicas do paciente, seu comprometimento sistêmico agravou-se com evolução do paciente para o óbito.

\section{Resultados}

Os três pacientes do sexo masculino apresentam média de idade de seis anos (variando entre 10 meses e 13 anos) e todos pertencem à classificação C3 (Centers for Disease Control - Atlanta - EUA 1994).

A média obtida entre a contagem de linfócitos CD4+ dos três casos foi de $67 \mathrm{cel} / \mathrm{ml}$ (variando entre 43-98 cels $/ \mathrm{mm}^{3}$ ); e a média da carga viral foi de 190.000 cópias $/ \mathrm{ml}$ (variando entre 53.600 e 460.000 cópias/ml).

Nos três casos, através da genotipagem, foi comprovada a resistência aos antiretrovirais inibidores análogos de nucleosídeos da transcriptase reversa e inibidores de protease como demonstrado nas Tabelas I e 2 .

\section{Dıscussão}

Desde que o primeiro caso de retinite por CMV em pacientes pediátricos foi publicado em $1986^{14}$, poucos têm sido os relatos na literatura. Com base nestes trabalhos, acreditava-se que esta população estaria bem menos exposta ao risco de desenvolvimento da retinite pelo CMV. Estudos existentes não estabelecem com exatidão níveis críticos de CD4+, abaixo dos quais o risco para o desenvolvimento de retinite entre os pacientes pediátricos seria maior. Du et al. (1999), após realizarem um estudo prospectivo com 1 I 6 pacientes pediátricos infectados pelo $H I V$, diagnosticaram retinite por CMV em quatro pacientes (3,4\%), todos com CD4+ abaixo de 20 cels $/ \mathrm{mm}^{3}$ e má aderência ao tratamento com antiretrovirais. Este estudo sugeriu que este seria o limite, a partir do qual deveria ser realizado exame oftalmoscópico de controle ${ }^{13}$.

Com o início da publicação dos primeiros casos de falência às drogas utilizadas no HAART e resistência aos antivirais, tanto na população adulta quanto na pediátrica, acredita-se que possa haver novamente uma mudança na morbidade e mortalidade tanto com relação à AIDS ${ }^{15,16}$, quanto com relação às doenças oportunistas, neste caso especificamente a retinite causada pelo $\mathrm{CMV}^{17}$.

Falência terapêutica ao uso dos antiretrovirais pode ser definida como: falência imuno-

\section{Figura 3 - Início da atividade da retinite pelo citomegalovírus no olho esquerdo. (Forma edematosa do CMV na ocasião do diagnóstico)}

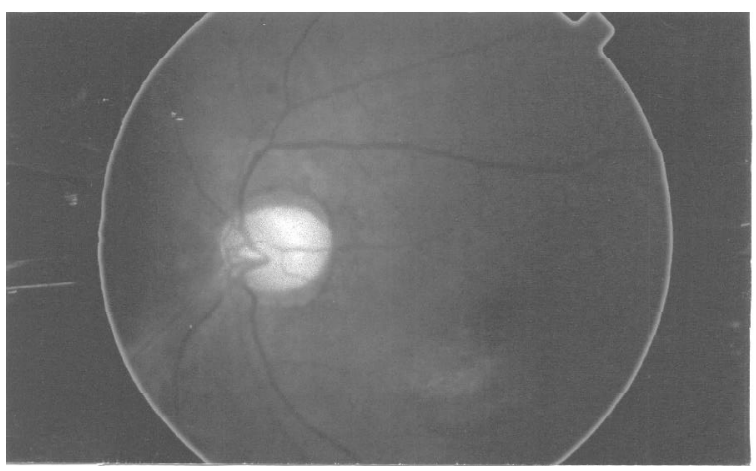

Figura 4 - Retinite típica com necrose subretiniana acometendo mácula e n. óptico do olho esquerdo (duas semanas após início do tratamento específico)

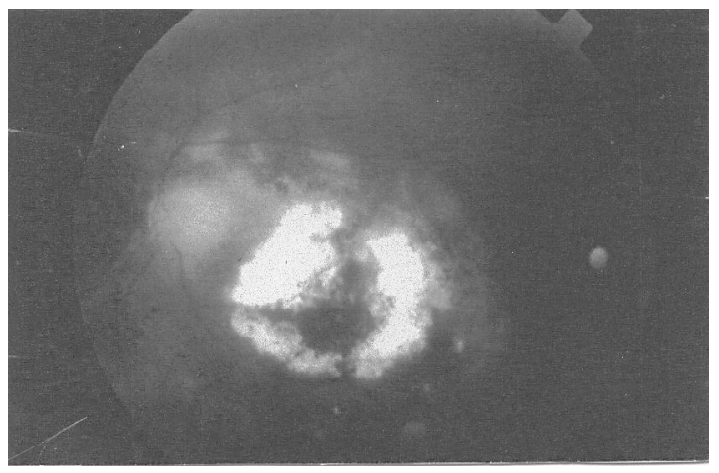

Tabela I - Sensibilidade ao uso de antiretrovirais inibidores análogos da transcriptase reversa em três pacientes pediátricos com AIDS e retinite pelo CMV em tratamento com HAART

\begin{tabular}{|c|c|c|c|}
\hline Inibidores da transcriptase reversa & Caso I & Caso 2 & Caso 3 \\
\hline AZT & $R$ & $R$ & $R$ \\
\hline D4T & $R$ & $R$ & $R$ \\
\hline DDI & $R$ & $R$ & $R^{*}$ \\
\hline 3TC & $R$ & $R$ & $R$ \\
\hline Abacavir & ND & ND & $S$ \\
\hline
\end{tabular}

$\mathrm{R}=$ Resistência completa; $\mathrm{R}^{*}=$ Resistência parcial;

$S=$ Sensível; ND = Não disponível

Tabela 2 - Sensibilidade ao uso de antiretrovirais inibidores de protease em três pacientes pediátricos com AIDS e retinite pelo $\mathrm{CMV}$ em tratamento com HAART

\begin{tabular}{lccc}
\hline Inibidores de protease & Caso I & Caso 2 & Caso 3 \\
Ritonavir & $R$ & $R$ & $R$ \\
Indinavir & $R$ & $R$ & $R$ \\
Nelfinavir & $R^{*}$ & $R$ & $R^{*}$ \\
Saquinavir & $N D$ & $R$ & $R^{*}$ \\
\hline
\end{tabular}

$\mathrm{R}=$ Resistência completa; $\mathrm{R}^{*}=$ Resistência parcial;

$S=$ Sensível; $N D$ = Não disponível. 
lógica (queda progressiva da contagem de células CD4+); falência clínica (progressão clínica da doença) e falência virológica (insucesso na tentativa de obter ou manter a máxima supressão virológica). Nos pacientes com importante resistência às drogas antiretrovirais, o objetivo principal passa a ser manter as melhores condições imunológicas e evitar a piora das condições clínicas, já que se torna praticamente impossível esperar sua completa supressão virológica.

Esta série de casos sugere que o início do quadro de falência terapêutica observado com relação às drogas do HAART tem colaborado de maneira decisiva para o surgimento de casos de retinite pelo CMV, visto que os pacientes têm desenvolvido resistência múltipla às drogas, com depleção dos linfócitos CD4+, aumento da carga viral e quadro ocular tão agressivo quanto aquele encontrado antes da era HAART, com necrose extensa e rapidamente progressiva, mesmo na vigência de tratamento com antivirais espećficicos.

Baseados nestes relatos tornam-se questionáveis os conceitos citados anteriormente na literatura com relação à incidência da retinite pelo citomegalovírus na população pediátrica e sua prevenção através de exames oculares de controle ${ }^{18}$, visto que os três pacientes apresentaram níveis de CD4+ acima de $40 \mathrm{cels} / \mathrm{mm}^{3}$, estavam em tratamento com inibidores de protease e análogos de nucleosídeos (HAART) e foram submetidos a tratamento da retinite com antiviral específico.

Os benefícios obtidos desde a introdução da era HAART divulgados através da literatura médica até o momento são, sem dúvida, sem precedentes dentro do quadro de evolução da AIDS. Entretanto, a abordagem terapểutica dos pacientes infectados tem se tornado complexa, não somente pelas inúmeras possibilidades de escolha das drogas, como também pela emergente resistência a elas e pelo crescimento dos efeitos colaterais induzidos pelo uso crônico dos agentes antiretrovirais ${ }^{19}$.

\section{Conclusão}

Baseados neste estudo, ressaltamos a importância de se colocar em discussão parâmetros utilizados como indicativos para o desenvolvimento da retinite pelo citomegalovírus (número de linfócitos CD4+ e aderência ao tratamento antiretroviral) nas crianças infectadas pelo HIV.

O exame de rotina para pacientes pedíátricos torna-se fundamental, independentemente de sua categoria imunológica e tratamento ou não com antiretrovirais, tanto pela escassez de estudos realizados neste grupo espećfico, quanto pela importância de seu prognóstico visual, dado o aumento considerável da sobrevida dos pacientes portadores do vírus da imunodeficiência humana (HIV).

\section{Conflito de interesse: não há.}

\section{SUMMARY}

Cytomegalovirus Retinitis in
Pediatric patients With AIDS ReCEIVING
HIGHLY active antiRetrovirus therapy

BACKGROUND. To describe three cases of cytomegalovirus retinitis occurring in HIVinfected children taking protease inhibitors combined with transcriptase inhibitors (HAART).

METHODS. Three cases ofHIV-infected children taking highly active antiretrovirus therapy (HAART) underwent an ocular examination at a university referral center - UNIFESP.

RESULTS. The average age was 6 years ( 10 months to 13 years old), and all of them were $C 3$ (CDC - Atlanta - EUA 1994). Median CD4 cell count and plasma HIV RNA were 67 cells $/ \mathrm{mm}^{3}$ (43 - 98 cells $/ \mathrm{mm}^{3}$ ) and 190.000 copies $/ \mathrm{ml}$ (53.600 - 460.000 copies $/ \mathrm{ml})$.

The three patients presented HAART failure and all of them were treated with anti-CMV agents without success.

CONCLUSION. The unprecedented benefits resulting from highly active antiretroviral therapy (HAART) have been well described. However, treatment failure has become increasingly complex, because of the aggres sive forms of opportunistic diseases like CMV retinitis, despite anti-CMV agents. Prompt diagnosis and treatment are essential to minimize the risk of longterm loss of vision for these infected children. [Rev Assoc Bras Med 2004; 50(3): 320-3]

KEY wORDS: AIDS. Child. HAART. Treatment failure. CMV retinitis/treatment. Case report.

\section{REFERÊNCIAS}

I. Muccioli C, Belfort Jr R, Lottemberg C, Lima J, Santos P, Kim M, et al. Achados oftalmológicos em AIDS: avaliação de 445 casos atendidos em um ano. Rev Assoc Med Bras 1994; 40: I 55-8.

2. Jabs DA, Green WR, Foox R, Polk FB, Bartlet JG. Ocular manifestations of Acquired Immune Deficiency Syndrome. Ophthalmology 1989; 96: 1092-9

3. Palella FJ Jr, Delaney KM, Moorman AC, Loveless MO, Fuhrer J. Satten GA, et al. The HIV outpatient study investigators: declining morbidity and mortality among patients with advanced human immunodeficiency virus infection. N Engl J Med 1998; 338:853-60.
4. Muccioli C, BelfortJr R. Manifestações oculares da AIDS: atlas e texto. Rio de Janeiro: Cultura Médica; 1998.

5. Veronesi R, Focaccia R, Lomar AV. HIV/AIDS: etiologia, patogenia e patologia clínica: tratamento e prevenção. São Paulo: Atheneu; 1999.

6. Holland GN, Pepose IS, Petit TH, Gottlieb MS, Yee RD, Foos RY. Acquired immunodeficiency syndrome: ocular manifestations. Ophthalmology 1983; 90:859-73.

7. Palestine AG, Rodrigues MM, Macher AM, Chan CC, Lane GC, Fauci AS, et al. Ophthalmic involvement in acquired immunodeficiency syndrome. Am J Ophthalmol 1 984; 97: | 33-42.

8. Gallant JL, Moore RD, Richman DD, Keruly J, Chaisson RE. Incidence and natural history of cytomegalovirus disease in patients with advanced human immunodeficiency virus disease treated with zidovudine. J Infect Dis 1992; 1 66: I 223-7.

9. Pertel P, Hirschtick R, Phair J, Chmiel J, Poggensee L, Murphy R. Risk of developing cytomegalovirus retinitis in persons infected with the human immunodeficiency virus, Acquir Immune Defic Syndr I 992: 5: I 069-74.

10. Whitcup SM, Fortin E, Nussemblat RB, Polis MA, Muccioli C, Belfort R Jr. Therapeutic effect of combination antiretroviral therapy on cytomegalovirus retinitis. JAMA 1997; 277: | 519-21.

II. Dimantas MAP, Peixoto LP, Duran C.G, Unonius N, Muccioli C. AIDS-related ocular manifestation 3 years after HAART. In: $5^{\text {th }}$ International Symposium on Uveitis; 2000 March 26-29, Buenos Aires, Argentina; 2000.

12. Dennehy PJ, Warman R, Flynn JT, Scoot GW, Masgrucci MT. Ocular manifestations in pediatric patients with acquired immunodeficiency syndrome. Arch Ophthalmol 1989; 107:978-82.

13. Du LT, Coats DK, Kline MW, Rosenblatt HM, Bohannon B, Contan. Incidence of presumed cytomegalovirus retinitis in $\mathrm{HIV}$-infected pediatric patients. | Aapos 1999; 3:245-9.

14. Daus W, Zimmer KP, Moller P. Bilateral cytomegalovirus retinitis in an infant with fatal congenital AIDS. Klin Monatsbl Augenheikd 1986: | 88:604-9.

15. Price P, Mathiot N, Krueger R, Stone S, Keane NM, French MA. Immune dysfunction and immune restoration disease in HIV patients given highly active antiretroviral therapy. J Clin Virol 200 I; 22:279-87.

16. Eshleman SH, Krogstad P, Jackson JB, Wang YG, Lee $\mathrm{S}, \mathrm{Wei} \mathrm{L}$, et al. Analysis of human immunodeficiency virus type I drug resistance in children receiving nucleoside analogue reverse-transcriptase inhibitors plus nevirapine, nelfinavir, or ritonavir. J Infect Dis 200 I; 183: 1732-8.

17. Jabs R, Enger C, Forman M, Dunn JP. Cytomegalovirus retinitis and viral resistance: ganciclovir resistance. CMV retinitis and viral resistance study group. J Infect Dis 1998; 177:770-3.

18. Baumal CR, Levin AV, Kavalec CC, Petric M, Khan $\mathrm{H}$, Read SE. Screening for cytomegalovirus retinitis in children. Arch Pediatr Adolesc Med 1996; I 50: | 186-92.

19. Gallant JE. Antiretroviral therapy: starting, continuing, and fixing. Medscape HIV/AIDS Annual Update $200 \mathrm{I}$.[online]. Available from: http://hiv.medscape.com/. Medscape/HIV.

Artigo recebido: 17/04/2003

Aceito para publicação: 19/09/2003 